\title{
The Effects of Isobutanul Addition on Bubble Size, Gas Holdup, Interfacial Area, Bubble Coalescence, and Transition Concentration in Dispersion Column
}

\author{
Fadi Zakariya Hanna and Ribwar Kermanj Abdulrahman
}

\begin{abstract}
The bubble coalescence and the transition concentration in a dispersion column have been experimentally studied in this study work by adopting isobutanol-water mixture as a liquid phase and air as a gas phase. The experimental work included the following experimental variables; the weight percent of isobutanol in water and superficial gas velocity of air. The using of two distributors single-orifice and multi-orifice, bubble size, gas holdup and gas-liquid interfacial area are measured. The experimental results have showed that the isobutanol transition concentration is successfully correlated as a function of superficial air velocity, $c_{t}=0.072079-0.006408 U_{g}+0.000425 U_{g}^{2}-0.00001 U_{g}{ }^{3}$. This equation gives mean deviation of $4.501 \%$.
\end{abstract}

Index Terms-Gas-liquid dispersion column, bubble coalescence, transition concentration.

\section{NOTATIONS}

$a=$ specific gas-liquid interfacial area, $\mathrm{mm}^{2} / \mathrm{mm}^{3}$

$c_{A}=$ isobutanol concentration, $\mathrm{kmol} / \mathrm{m}^{3}$

$c_{t}=$ transition concentration of isobutanol, $\mathrm{kmol} / \mathrm{m}^{3}$

$d_{B i}=$ diameter of bubbles of size $i, \mathrm{~mm}$

$d_{o}=$ orifice diameter of perforated plate, $\mathrm{mm}$

$d_{v s}=$ sauter mean diameter of bubbles, $\mathrm{mm}$

$K=$ number of variables in the system

$n=$ number of orifices in perforated plate

$n_{i}=$ number of bubbles of size $i$

$N=$ number of experiments

$r_{c}=$ correlation coefficient

$U_{g}=$ superficial gas velocity of air, $\mathrm{mm} / \mathrm{s}$

$W t \%=$ weight percent of isobutanol in water, $\%$

$x_{1}, x_{2}=$ coded or independent variables of polynomial equation

$Z_{\mathrm{o}}, Z_{1}, Z_{3}=$ liquid levels in the manometers, $\mathrm{mm}$.

\section{Greek Letters:}

$\varepsilon_{g}=$ gas holdup

$\psi=$ coalescence percentage, $\%$

Manuscript received October 26, 2013; revised March 20, 2014.

F. Z. Hanna is with Koya University, Kurdistan Region of Iraq (e-mail: fadi.hanna@koyauniversity.org).

R. K. Abdulrahman is with Koya University, Kurdistan Region of Iraq (e-mail: ribwar.abdulrahman@koyauniversity.org).

\section{INTRODUCTION}

The most important process in a bubble column is the formation of a gas at the sparger. The smaller the bubbles, the larger are the area for mass transfer between the gas and liquid phases. Bubble swarm behavior in a bubble column is mainly determined by the gas superficial velocity (Heijnen and Riet [1]). Bubble size, bubble rise velocity, bubble size distribution, and liquid and bubble velocity profile have a direct bearing on the performance of bubble columns (Shah $e t$ al. [2]). Akita and Yoshida [3] determined the bubble size distribution using a photographic technique. The gas was sparger through perforated plates and single-orifice using various liquids (water, aqueous and pure glycol, methanol, carbon tetrachloride). Saxena A. C and Sexena S. C [4] studied the bubble size distribution in bubble column for the air-water system as a function of gas velocity at room temperature in the two bubble columns. High speed cinephotography and fiber optic probe techniques were used to measure bubble size. They suggest that the bubble size may be dependent on column diameter with smaller bubbles for narrower columns. The bubble size appears to be smaller at the column wall than at distance away from the wall. Gas holdup is one of the most important parameters characterizing the hydrodynamics of bubble columns. It can be defined as the percentage by volume of the gas in the two or three phases mixture in the column (Shah et al. [2]). The influence of gas velocity on gas holdup for alcohols aqueous solutions is reported by Posarac and Tekic [5]. They found that gas holdup value increase with increasing gas velocity and depend significantly on the type of alcohol added. Ruzicka et al. [6] studied experimentally the effect of the column size (height and diameter) on the stability of the homogeneous flow regime. The stability was expressed by values of the critical gas holdup and critical gas flow rate. They concluded from their results that the gas holdup values increases with increasing gas flow rate, and these values are mainly dependent on the bubble column diameter. Zahradnik et al. [7] studied the effect of aliphatic alcohols with different lengths of carbon chain ranging from methanol to octanol on bubble coalescence and gas holdup. The gas-liquid interfacial area is an important design variable in bubble column which depend on the geometry of the apparatus, the operating conditions, and the physical properties of liquid media (Shah et al. [2]). Bubble coalescence plays a significant role in determining bubble size distribution, gas holdup, interfacial area, and bubble rise velocity, which govern the performance of bubble columns and distillation towers (Kim and Lee [8]). Coalescence of bubbles in gas-liquid dispersions will be 
inhibited, when the liquid phase is not pure component, but a mixture, as has been reported by Marrucci and Nicodemo [9]. Zahradnik et al. [10] studied the link the coalescence behavior of bubbles in aqueous electrolyte solutions with the character of gas-liquid beds generated in bubble column reactors and with corresponding values of bubble bed voidage. The experimental programme, performed with the set of nine inorganic salts, included determination of the bubble coalescence frequency in a coalescence cell and measurement of gas holdup in a sieve tray bubble column reactor of $0.14 \mathrm{~m}$ inside diameter. The aim of the present work is to study the effect of addition of isobutanol on the performance of dispersion column, gas hold up, bubble size, gas-liquid interfacial area, were they effected directly by the bubble coalescence frequency. The transition concentration is predicted from bubble coalescence frequency were it is very important parameters that effect the mass transfer in the bubble column.

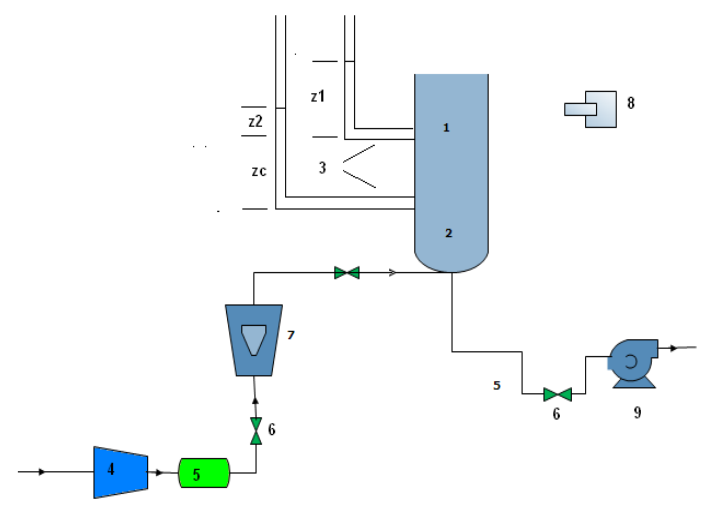

(a)

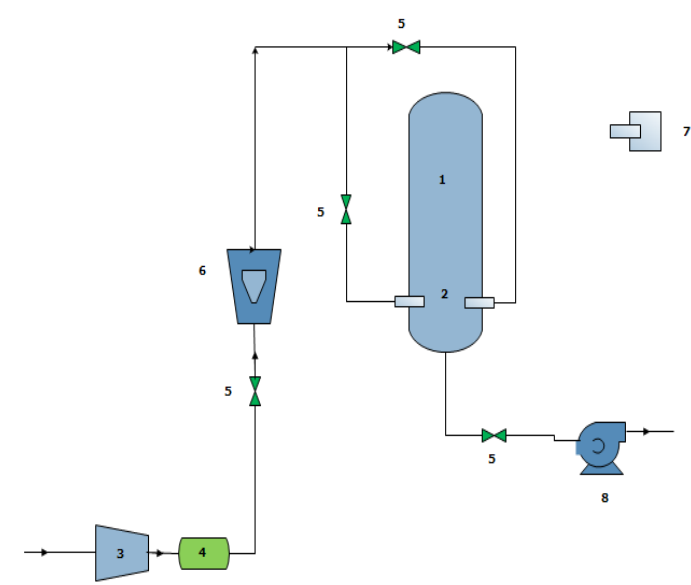

(b)

Fig. 1. (a) Experimental set-up: (1) bubble column (2) perforated plate (3) manometers (4) air compressor (5) air filter (6) regulating valves (7) rotameter (8) digital camera (9) centrifugal pump (b) Scheme of coalescence cell (1) bubble column (2)capillaries (3) air compressor (4) air filter (5) regulating valves (6) rotameter (7) digital camera (8) centrifugal pump.

\section{EXPERIMENTAL SECTION}

Photographing the bubbles and studying the hydrodynamics of bubbles were performed in perspex column of $75 \mathrm{~mm}$ inside diameter and $2000 \mathrm{~mm}$ in height, (shown in Fig. 1(a)).Two kind of perforated plates were used, single-orfice (plate A) $\left(d_{\mathrm{o}}=2 \mathrm{~mm}\right)$, and multi-orfice (plate B) $\left(d_{0}=0.5 \mathrm{~mm}\right.$, and $\left.n=45\right)$ in a triangular pitch. The bubble column opened to the atmosphere and operated continuously with respect to the gas phase and batch wise with respect to the liquid phase. The liquid used in this work is aqueous solutions of isobutanol. The clear liquid height was $1500 \mathrm{~mm}$, and liquid temperature was kept at $26{ }^{\circ} \mathrm{C}$. The gas phase (air) was fed to the bottom of the column through the distributor, after the flow rate had been measured with rotameter. The liquid was discharged from the bottom of the column using centrifugal pump. While the bubble coalescence was performed in the other perspex column of $75 \mathrm{~mm}$ inside diameter and $1500 \mathrm{~mm}$ in height, (shown in Fig. 1(b)). The head of liquid over the gas injection region was $1200 \mathrm{~mm}$. Pairs of bubbles were formed simultaneously at opposite orifices of the two stainless steel capillaries $2 \mathrm{~mm}$ in diameter, the distance of orifices was $10 \mathrm{~mm}$. One thousand bubble pairs were contacted in each experimental run and the coalescence percentage was then directly obtained as the number of coalescing bubble pairs. The transition concentration, define by Lessard and Zieminski [11] as the concentration corresponding to $50 \%$ coalescence, were then determined from the graphs ( $\psi$ vs. $c_{A}$ ) showing dependence of the coalescence percentage on the ethanol concentration.

When the bubble column is operated, the volume fraction of gas bubbles in the column can be computed from the heights of liquid levels in the manometer, by following Eq. (1), Jeng et al. [12]:

$$
\varepsilon_{g}=\left(Z_{1}-Z_{2}\right) / Z_{o}
$$

The photographs of bubbles are taken by digital camera at the speed of 500frames/s, using a steel ball to calibrate the bubble shape. The diameter of each bubble is measured on the photograph and sauter mean diameter is computed, by following Eq. (2), Jeng et al. [12]:

$$
d_{v s}=\left(\sum n_{i} d_{B i}^{3}\right) /\left(\sum n_{i} d_{B i}^{2}\right)
$$

Specific gas-liquid interfacial area per unit volume of the dispersion column was obtained from Eq. (3), Jeng et al. [12]:

$$
a=6 \varepsilon_{g} / d_{v s}
$$

The experimental parameters of bubble size (sauter mean diameter), gas holdup, and gas-liquid interfacial area were designed using the centrol composite rotatable design with the following ranges of process variables:

1. Weight percent of isobutanol in water: $(0.05-0.95)$ Wt $\%$.

2. Superficial gas velocity of air $\left(U_{g}\right):(1.5-28.5) \mathrm{mm} / \mathrm{s}$.

Using two perforated plate [single-orifice (plate A), and multi -orifice (plate B)].

A preliminary step is to setup the relationships between the coded levels and the corresponding real variables. The general relationship is following, (Montgomery [13], Peters and Timmerhaus [14]):

$$
X_{\text {coded }}=\frac{X_{\text {actual }}-X_{\text {center }}}{\left[\frac{X_{\text {center }}-X_{\text {min imum }}}{\sqrt{K}}\right]}
$$

The number of experiments $N$ needed is estimated according to the following equation, (Montgomery [13], 
Peters and Timmerhaus [14]):

$$
N=2^{K}+2 K+1
$$

For the purpose of a second-order polynomial regression the central composite rotatable design for two variables was used. The coded levels are related to real process variables as follows:

$$
\begin{gathered}
X_{1}=\frac{W t \%-0.5}{0.3182} \\
X_{2}=\frac{U_{g}-15}{9.5459}
\end{gathered}
$$

\section{RESULTS AND DISCUSSION}

\section{A. Use Non-Linear Regression Analysis}

Second order polynomial regression analysis of the objective function (sauter mean diameter, gas holdup, gas-liquid interfacial area, and bubble coalescence percentage) gave Eqs. (8) to (13) respectively. In the analysis of the experimental results it is possible to determine not only the effect of each individual variable but also the way in which each variable effect depends on the other variables (i.e. interaction). A complete regression results with a computer program named "Statistica".

\section{For Plate (A):}

$d_{v s}=4.299955-1.01878 X_{1}-0.188403 X_{2}-0.237526 X_{1}^{2}$ $+0.012549 X_{2}^{2}-0.05 X_{1} X_{2}$

Mean deviation $=5.04 \%$

Correlation coefficient $\left(r_{c}\right)=0.976$

$\varepsilon_{g}=0.384505+0.1093791 X_{1}+0.01884 X_{2}-0.008504 X_{1}^{2}$

$-0.008504 X_{2}^{2}+0.005 X_{1} X_{2}$

Mean deviation $=3.065 \%$

Correlation coefficient $\left(r_{c}\right)=0.989$

$$
\begin{aligned}
a= & 0.536559+0.412624 X_{1}+0.054318 X_{2}+0.200963 X_{1}^{2} \\
& -0.022438 X_{2}^{2}+0.033508 X_{1} X_{2}
\end{aligned}
$$

Mean deviation $=8.055 \%$

Correlation coefficient $\left(r_{c}\right)=0.986$

\section{For Plate (B):}

$d_{v s}=3.559963-0.845203 X_{1}-0.154991 X_{2}-0.194397 X_{1}^{2}$ $+0.013166 X_{2}^{2}-0.04 X_{1} X_{2}$

Mean deviation $=4.999 \%$

Correlation coefficient $\left(r_{c}\right)=0.977$

$\varepsilon_{g}=0.427029+0.121356 X_{1}+0.020886 X_{2}-0.009784 X_{1}^{2}$ $-0.009784 X_{2}^{2}+0.005478 X_{1} X_{2}$
Mean deviation $=3.021 \%$

Correlation coefficient $\left(r_{c}\right)=0.989$

$$
\begin{aligned}
a= & 0.624825+0.382013 X_{1}+0.09886 X_{2}+0.108246 X_{1}^{2} \\
& -0.016472 X_{2}^{2}+0.0956 X_{1} X_{2}
\end{aligned}
$$

Mean deviation $=11.683 \%$

Correlation coefficient $\left(r_{c}\right)=0.985$

\section{B. Influence of Process Variables on $d v s, \varepsilon g, a$, and $\psi$.}

Two variables were studied in dispersion column: weight percent of isobutanol in water, and superficial gas velocity of air, for two perforated plates (A) and (B). The meanings of code numbers for all Figures are given below (Table I).

TABLE I: WORKING RANGE OF CODED AND CORRESPONDING REAL

\begin{tabular}{|c|c|c|}
\hline Coded Level & $\boldsymbol{W t}(\boldsymbol{\%})$ & $\boldsymbol{U}_{\boldsymbol{g}}(\mathbf{m m} / \mathbf{s})$ \\
\hline-1.414 & 0.05 & 1.5 \\
\hline-1 & 0.1818 & 5.4541 \\
\hline 0 & 0.5 & 15 \\
\hline 1 & 0.8182 & 24.5459 \\
\hline 1.414 & 0.95 & 28.5 \\
\hline
\end{tabular}

Experimental results verify from Fig. 2 to Fig. 7, the effect of weight percent of isobutanol in water on sauter mean diameter, gas holdup, and gas-liquid interfacial area for two perforated plates (A) and (B). The sauter mean diameter decreases with increasing weight percent of isobutanol in water, but the gas holdup, and gas-liquid interfacial area increase with increasing weight percent of isobutanol in water, for two perforated plates, but in perforated plate (B) they had higher values than those of perforated plate (A). This increase can be attributed to the addition of small amount of isobutanol to the water in a bubble column has the effect of retarding the coalescence of the gas bubbles. This makes the number of gas bubbles per unit volume larger, size smaller, terminal rising velocity slower, and residence time in the column liquid longer, and consequently the volume fraction occupied by the gas phase, and gas-liquid interfacial area per unit volume larger. This phenomenon can be explained as isobutanol in water acts as a surfactant which hinders bubble coalescence by accumulating at the gas-liquid interface and orienting their hydrophilic group into liquid film surrounding the gas bubble and thus creating repulsive electric forces when two bubbles come close to each other. The concentration of the hydrophilic molecules at the surface increases with surfactant concentration and results in a lower surface tension. These notation supported by Keitel and Onken [15], and Wilkinson et al. [16].

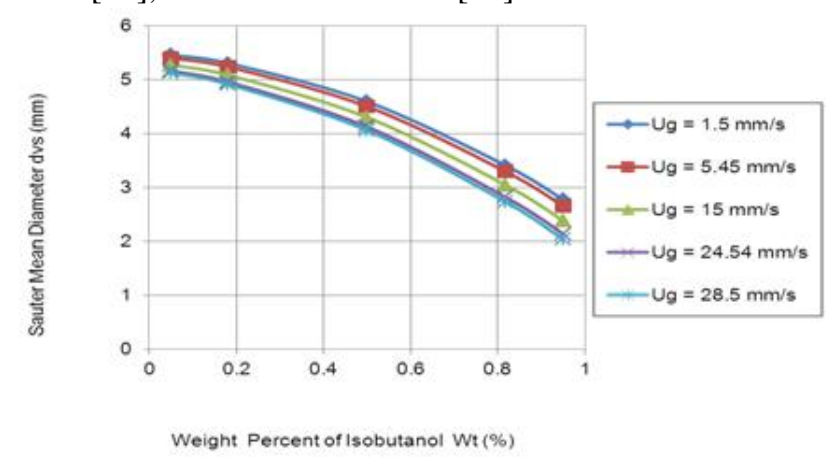

Fig. 2. Influence of isobutanol addition on sauter mean diameter for plate (A). 


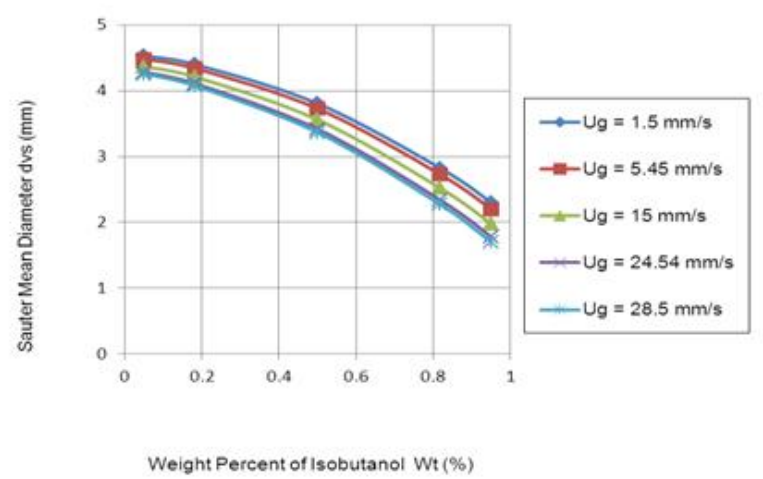

Fig. 3. Influence of isobutanol addition on sauter mean diameter for plate (B).

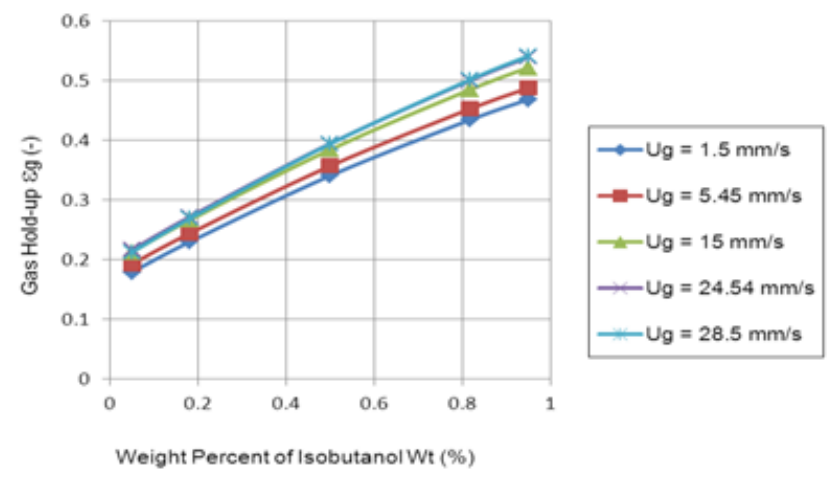

Fig. 4. Influence of isobutanol addition on gas hold-up for plate (A).

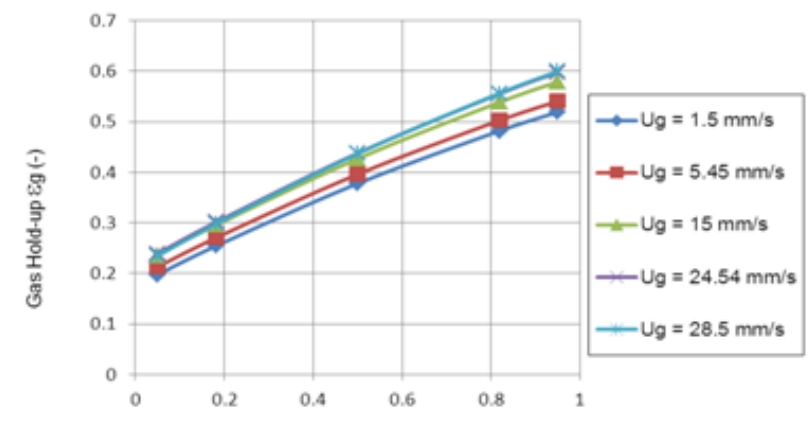

Weight Percent of I sobutanol Wt (\%)

Fig. 5. Influence of isobutanol addition on gas hold-up for plate (B).

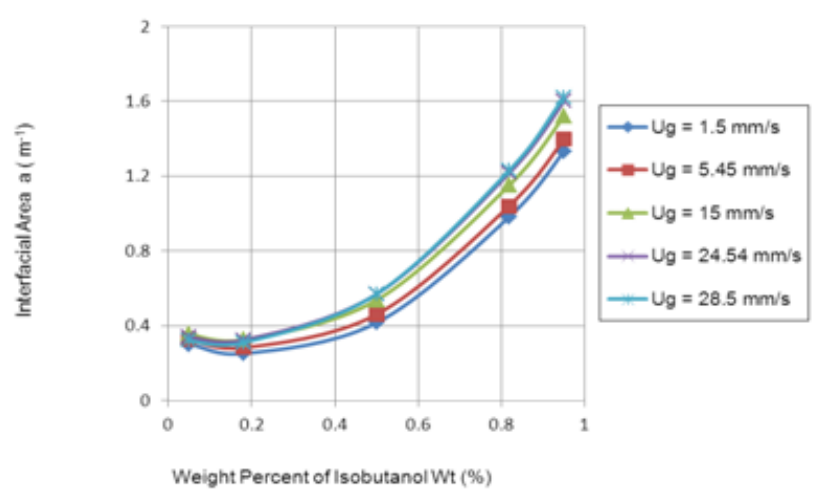

Fig. 6. Influence of isobutanol addition on interfacial area for plate (A).

Fig. 8-Fig. 13 respectively show the influence of superficial gas velocity of air on sauter mean diameter, gas holdup, and gas-liquid interfacial area, for two perforated plates (A) and (B). The sauter mean diameter decreases with increasing superficial gas velocity of air, but the gas holdup, and gas-liquid interfacial area increase with increasing superficial gas velocity of air, for two perforated plates. This increase is attributed to the fact that in higher superficial gas velocity of air, small bubbles are formed with a lower rising velocities leading to a large residence time and consequently higher values of gas holdup, and these small bubbles have large gas-liquid interfacial area. This was reported by Zahradnik et al. [7].

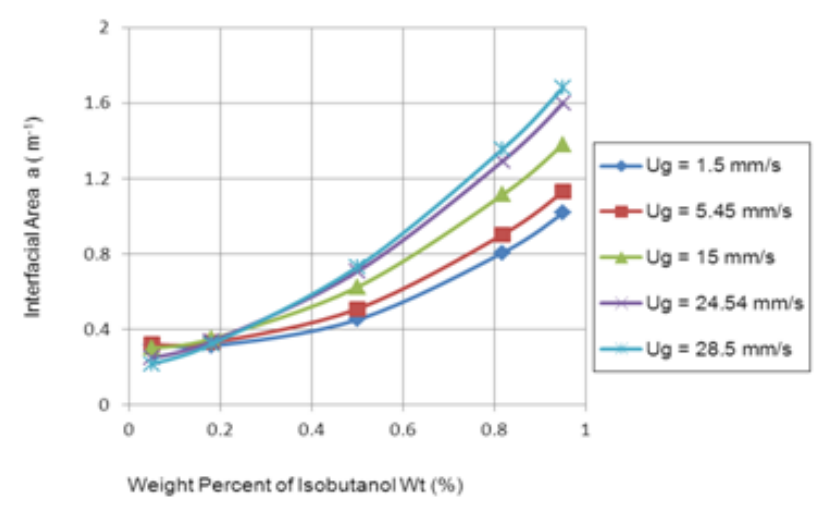

Fig. 7. Influence of isobutanol addition on interfacial area for plate(B).

The effect of design parameter of perforated distributing plates has been demonstrated by all Figures given below. The values of gas holdup and gas-liquid interfacial area for perforated plate $(B)$ were higher than those for perforated plate (A). The difference between two perforated plates is due to the smaller orifice diameter in the perforated plate (B), higher number of bubble are formed per unit volume, and the bubble size produced would be smaller and large gas-liquid interfacial areas lead to a higher gas holdup as compared with that in a perforated plate (A). This was reported by Zahradnik and Fialova [17], and Zahradnik et al. [18].

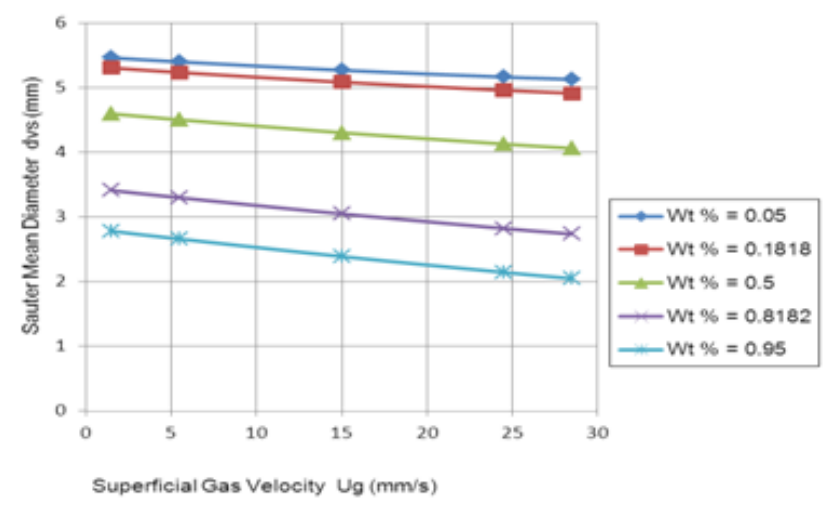

Fig. 8. Influence of superficial gas velocity on sauter mean diameter for plate (A).

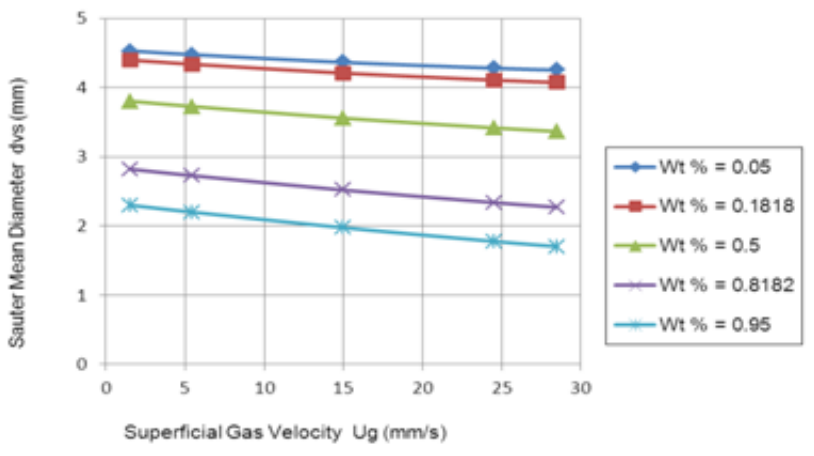

Fig. 9. Influence of superficial gas velocity on sauter mean diameter for plate (B). 


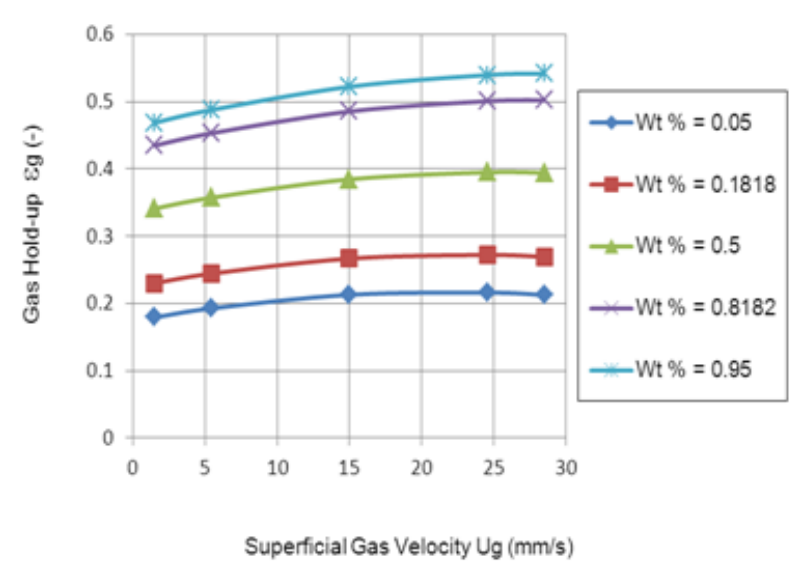

Fig. 10. Influence of superficial gas velocity on gas hold-up for plate (A).

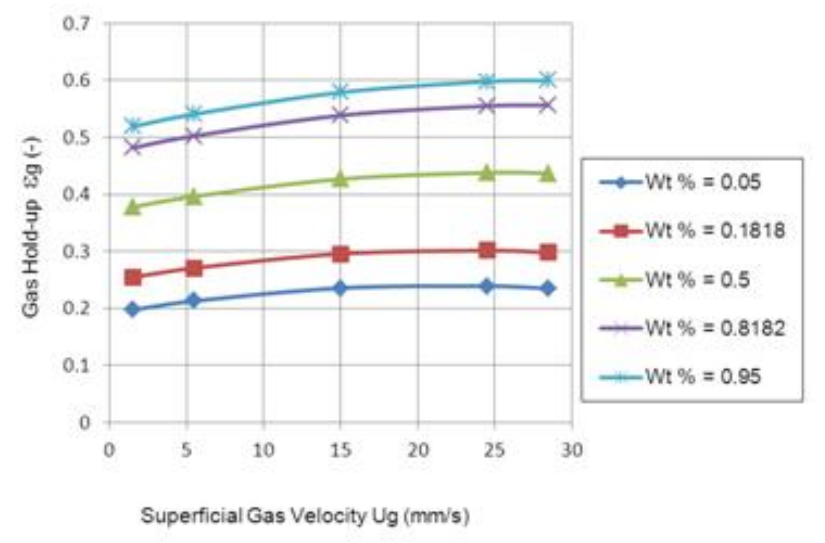

Fig. 11. Influence of superficial gas velocity on gas hold-up for plate (B).

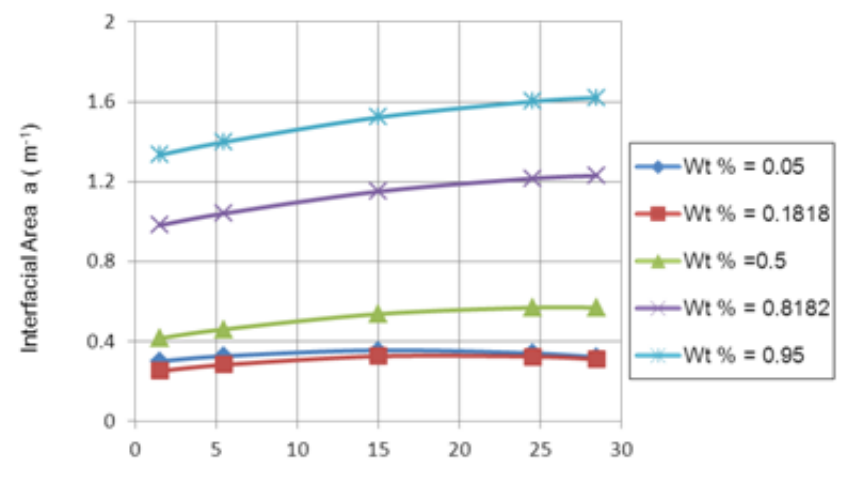

Superficial Gas Velocity Ug $(\mathrm{mm} / \mathrm{s})$

Fig. 12. Influence of superficial gas velocity on interfacial area for plate (A).

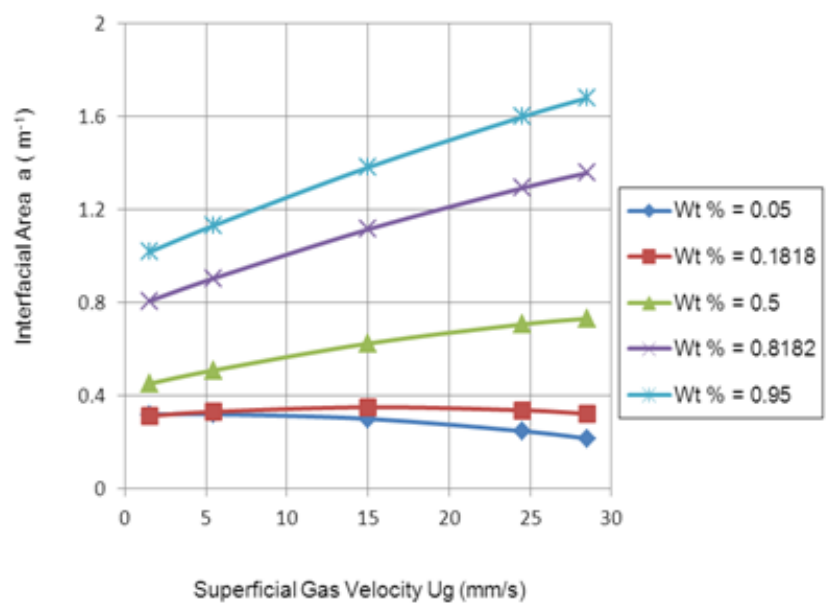

Fig. 13. Influence of superficial gas velocity on interfacial area for plate (B).
Bubble coalescence percentage, $\psi \%$ is the number of occurrence of coalescence within a certain volume element of the column per unit time, and their values were calculated by photographic technique. Results of bubble coalescence measurements are summarized in Fig. 14 and Fig. 15 in which values of the bubble coalescence percentage are plotted against the concentration of isobutanol in water, and superficial gas velocity of air. The bubble coalescence percentage decrease with increasing isobutanol concentration in water, and superficial gas velocity of air. The value of transition concentration $\left(c_{t}\right)$ obtained experimentally from Fig. 14 by projection. The transition concentration was defined as the concentration resulting in $50 \%$ coalescence frequency. This was reported by Lessard and Zieminski [11].

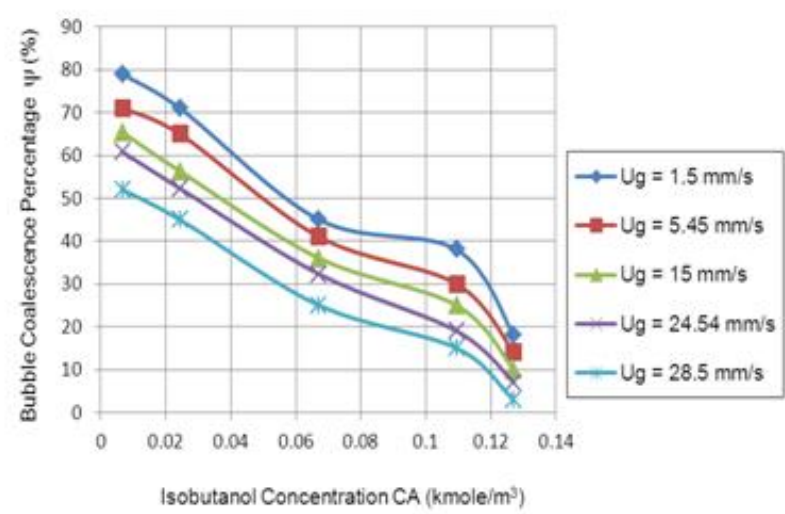

Fig. 14. Influence of isobutanol concentration on bubble coalescence percentage.

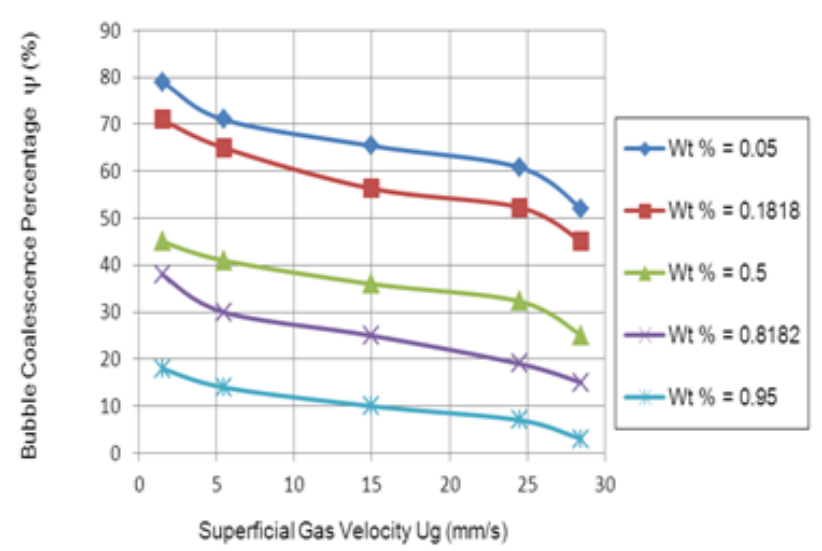

Fig. 15. Influence of superficial gas velocity on bubble coalescence percentage.

Analysis of experimental data showed that, within the experimental set, the isobutanol transition concentration was successfully correlated as a function of superficial gas velocity of air:

$c_{t}=0.072079-0.006408 U_{g}+0.000425 U_{g}^{2}-0.00001 U_{g}^{3}$

Mean deviation $=4.501 \%$

Correlation coefficient $\left(r_{c}\right)=0.996$

Comparison shown in Table II proves good agreement of experimental $c_{t}$ data with those calculated from Eq.(14), for empirical coefficients $0.072079,-0.006408,0.000425$, and -0.0001 determined from experimental data by non-linear regression. 
TABLE II: TRANSITION CONCENTRATION OF THE ISOBUTANOL ADDITION TO THE WATER

\begin{tabular}{|c|c|}
\hline $\begin{array}{c}\boldsymbol{c}_{\boldsymbol{t}}(\boldsymbol{e x p} \mathbf{.}) \\
\mathbf{k m o l} / \mathbf{m}^{\mathbf{3}}\end{array}$ & $\begin{array}{c}\boldsymbol{c}_{\boldsymbol{t}}(\boldsymbol{c a l} . \mathbf{.}) \\
\mathbf{k m o l} / \mathbf{m}^{\mathbf{3}}\end{array}$ \\
\hline 0.0625 & 0.06339 \\
\hline 0.05 & 0.048221 \\
\hline 0.0375 & 0.039278 \\
\hline 0.03125 & 0.029473 \\
\hline 0.0125 & 0.013387 \\
\hline
\end{tabular}

\section{CONCLUSION}

1) A surface active additives (i.e. isobutanol) in an effective means of improving the operating efficiency of bubble column, has the effect of retarding the coalescence of gas bubbles.

2) The bubble size (sauter mean diameter) is found to decrease with increasing weight percent of isobutanol in water, and superficial gas velocity of air, whereas the gas holdup is found increased resulting in an increase in gas-liquid interfacial area.

3) When central composite rotatable design technique was used, a relationship was found between process variable (Wt, and $\left.U_{g}\right)$ and $\left(d_{v s}, \varepsilon_{g}\right.$, and $a$ ) was obtain for two perforated plates (A), and (B).

4) Transition concentration of isobutanol, characterizing suppression of coalescence in isobutanol aqueous solutions, and isobutanol concentration was correlated as a function of superficial gas velocity of air.

5) The relation between the transition concentration of isobutanol and superficial gas velocity was polynomial equation.

\section{REFERENCES}

[1] J. J. Heijnen and K. V. Riet, "Mass transfer, mixing and heat transfer phenomena in low viscosity bubble column reactors," The Chemical Engineering Journal, vol. 28, issue 2, pp. B21-B42, April 1984.

[2] T. T. Shah, B. G. Kelkar, S. P. Godbole, and W. D. Deckwer, "Design parameters estimations for bubble column reactors," American Institute for Chemical Engineers journal, vol. 28, issue 3, pp. B354-B379, March 1986.

[3] K. Akita and F. Yoshida, "Bubble size, interfacial area, and liquid phase mass transfer coefficients in bubble columns," Industrial and Engineering Chemistry Process Design and Development, vol. 13, issue 84, pp. B84-B91, May 1974.

[4] A. C. Saxena and S. C. Saxena, "Bubble size distribution in bubble columns," The Canadian Journal of Chemical Engineering, vol. 68, issue , pp. 159-161, March 1990.

[5] D. Posarac and M. N. Tekic, "Gas holdup and volumetric mass transfer coefficient in bubble columns with dilute alcohol solutions," American Institute for Chemical Engineers journal, vol. 33, issue 3, pp. 497-499, November 1987.

[6] M. C. Ruzicka, J. Drahos, M. Fialova, and N. H. Thomas, "Effect of bubble column dimensions on flow regime transition," Chemical Engineering Society, vol. 56, issue 2, pp. 6117-6124, February 2001.

[7] J. Zahradnik, G. Kuncova, and M. Fialova, "The effect of surface active additives on bubble coalescence and gas holdup in viscous aerate batches," Chemical Engineering Society, vol. 54, issue 1, pp. 2401-2408, January 1999.

[8] J. W. Kim and W. K. Lee, "Coalescence behavior of two bubbles in stagnant liquids," Journal of Chemical Engineering Japan, vol. 20, issue 5, pp. 448-453, March 1987.
[9] G. Marrucci and L. Nicodemo, "Coalescence of gas bubbles in a aqueous solutions of in organic electrolytes," Chemical. Engineering Society, vol. 22, issue 2, pp.1257-1265, April 1967.

[10] J. Zahradnik, M. Fialova, F. Kastanek, K. D. Green, and N. Thomas, "The effect of electrolytes on bubble coalescence and gas holdup in bubble column reactors," Transactions of IChemE Journal, vol. 73, issue 2, pp. 341-346, April 1995.

[11] R. D. Lessard and S. A. Zieminski, "Bubble coalescence and gas transfer in aqueous electrolytic solutions," Industrial \& Engineering Chemistry Fundamentals, vol. 10, issue 1, pp. 260-289, January 1971.

[12] J. J. Jeng, J. R. Maa, and Y. M. Yang, "Surface effects and mass transfer in bubble column," Industrial \& Engineering Chemistry Process Design and Developments, vol. 25, issue 4, pp. 974-978 April 1986.

[13] D. C. Montgomery, Design and analysis of experiments, John Wiley and Sons, New York, ch. 15, 445-461, 1976

[14] M. S. Peters and K. D. Timmerhaus, Plant design and economics for chemical engineers, Mc Graw-Hill, Kogakusha, $2^{\text {nd }}$ ed., ch. 16, 702. 1987.

[15] G. Keitel and U. Onken, "Inhibition of bubble coalescence by solutes in air/water dispersions," Chemical Engineering Society, vol. 37, issue 11, pp. 1635-1638, March 1982.

[16] P. M. Wilkinson, A. P. Spek, and L. L. Van Dierendonck, "Design parameters estimation for scale-up of high pressure bubble columns," American Institute for Chemical Engineers journal, vol. 38, issue 2, pp. 544-554, December 1992.

[17] J. Zahradnik and M. Fialova, "The effect of bubbling regime on gas and liquid phase mixing in bubble column reactors," Chemical Engineering society, vol. 51, issue 10, pp. 2491-2500, December 1996.

[18] J. Zahradnik, M. Fialova, M. Ruzicka, J. Drahos, F. Kastanek, and N. Thomas, "Duality of the gas-liquid regimes in bubble column reactors," Chemical Engineering Society Journal, vol. 52, issue 22, pp. 3811-3826, April 1997.

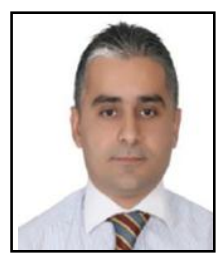

Fadi Z. Hanna is an assistant professor of chemical engineering in the Department of Chemical Engineering, where he joined the work at Koya University since 2011. Before that he was an assistant professor at The University of Technology, Baghdad, Iraq, where he was a lecturer in Chemical Engineering Department (2002-2011). He gained a B.Sc. degree in chemical engineering from University of Technology in 1997, M.Sc. degree in chemical engineering from University of Technology in 2000, and Ph.D. degree in chemical engineering from University of Technology in 2004. He started his academic teaching in 2004 when he joined the work at the University of Technology, Baghdad, as a lecturer in the Department of Chemical engineering. In 2011 he joined the Koya University, Kurdistan Region, Erbil as teaching staff of Chemical Engineering Department. He has research activities are multiphase flow, heat transfer (i.e., type of heat exchanges), thermodynamics (i.e., phase change), mass transfer (i.e., absorption columns), type of reactors (i.e., batch, semibatch, continuous stirrer tank reactor and plug flow reactor) and process control on many chemical engineering units.

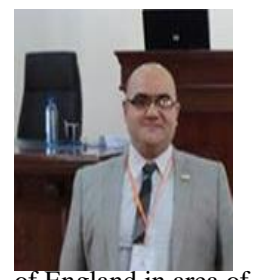

Ribwar Abdulrahman has extensive experience of research and teaching within the area of Natural gas processing and related fields, having worked at Koya University since 2006 when the Chemical Engineering Department was established in that year and his current role as assistant lecturer. He gained his master degree with distinction at United Kingdom master level from Teesside University in the northern of England in area of Petrochemical engineering. 